\title{
BMJ Open Interventions addressing risk factors of ischaemic heart disease in sub-Saharan Africa: a systematic review
}

\author{
Jennifer Ebireri, ${ }^{1}$ Adewale V Aderemi, ${ }^{2}$ Nicholas Omoregbe, ${ }^{3}$ Davies Adeloye ${ }^{4,5}$
}

To cite: Ebireri J, Aderemi AV, Omoregbe N, et al. Interventions addressing risk factors of ischaemic heart disease in sub-Saharan Africa: a systematic review. BMJ Open 2016;6:e011881.

doi:10.1136/bmjopen-2016011881

- Prepublication history and additional material is available. To view please visit the journal (http://dx.doi.org/ 10.1136/bmjopen-2016011881).

Received 14 March 2016 Revised 14 June 2016 Accepted 15 June 2016
CrossMark

For numbered affiliations see end of article.

Correspondence to Dr Davies Adeloye; bummyadeloy@gmail.com

\section{ABSTRACT}

Background: Ischaemic heart disease (IHD) is currently ranked eighth among the leading causes of deaths in sub-Saharan Africa (SSA). Yet, effective population-wide preventive measures targeting risks in the region are still largely unavailable. We aimed to review population-wide and individual-level interventions addressing risk factors of $\mathrm{HD}$ among adults in SSA.

Methods: A systematic search of MEDLINE, EMBASE, Global Health and AJOL was conducted to identify studies focusing on population-wide and individuallevel interventions targeting risks of IHD among adults in SSA. We conducted a detailed synthesis of basic findings of selected studies.

Results: A total of 2311 studies were identified, with only 9 studies meeting our selection criteria. 3 broad interventions were identified: dietary modifications, physical activity and community-based health promotion measures on tobacco and alcohol cessation. 3 studies reported significant reduction in blood pressure (BP), and another study reported statistically significant reduction in mean total cholesterol. Other outcome measures observed ranged from mild to no reduction in BP, blood glucose, body mass index and total cholesterol, respectively.

Conclusions: We cannot specify with all certainty contextually feasible interventions that can be effective in modifying IHD risk factors in population groups across SSA. We recommend more research on IHD, particularly on the understanding of the burden, geared towards developing and/or strengthening preventive and treatment interventions for the disease in SSA.

\section{INTRODUCTION}

The burden of cardiovascular diseases (CVDs) has consistently increased across many world regions over the last three

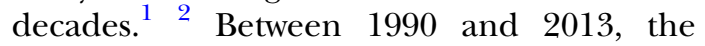
Institute for Health Metrics and Evaluation reported a median percentage change of CVDs at $40.8 \%$ and $89.2 \%$ for global deaths and years lived with disabilities, respectively. ${ }^{3} 4$ Increasing cases and deaths from CVDs, especially Ischaemic Heart Disease (IHD), have

\section{Strengths and limitations of this study}

- This study provides an insight into interventions targeting known risks of ischaemic heart disease (IHD) in selected African population groups.

- This study identifies substantive gaps in research and evidence for informed policy decisions on IHD in sub-Saharan Africa.

- Dietary modification, physical activity, health education and health promotion measures have been effective IHD preventive strategies in specific African population groups.

- We still cannot generalise and recommend identified IHD interventions to many African settings, especially due to varying degrees of heterogeneity within and across several African population groups.

also been reported among young and active adults globally. ${ }^{5}$ Global estimates suggest the figures to be about 93 million cases and 8.1 million deaths from IHD in 2013. ${ }^{34}$ In Africa, IHD accounted for 361000 deaths in 2005, and is currently ranked eighth among the top causes of deaths in the region. ${ }^{6}$ In sub-Saharan Africa (sSA) alone, it has been estimated that mortality from IHD may rise from the current rates by about $70 \%$ and $74 \%$ among African men and women, respectively, by $2030 .^{7}$ Increasing sedentary lifestyles, tobacco smoking, alcohol consumption, unhealthy diets and the fast rate of urbanisation and epidemiological transition across many African settings have been strongly indicated. ${ }^{58}$

The 2011 United Nations high-level meeting on non-communicable diseases (NCDs) focused on developing a comprehensive policy framework for the prevention and control of NCDs globally, especially across Africa and many low-income and middle-income countries, where the burden is fast increasing. ${ }^{9}$ Current reports from Africa show that public health response, access to health services, and availability of effective interventions and treatment options 
for NCDs, including IHD, are relatively poor. ${ }^{10}{ }^{11}$ Cost-effective interventions have been described in many high-income settings. ${ }^{12} 13$ Health education, improving access to screening and detection of IHD, deploying inexpensive technologies to arrive at diagnosis and providing affordable medications for prevention and treatment of heart attacks, have all been practised in many developed countries with success. ${ }^{12}{ }^{14}$ In sSA, substantive gaps exist in terms of implementation of many of these interventions due to weak primary healthcare and health systems, and poor political will. ${ }^{6}{ }^{15}$ Moreover, only a few studies, reviews and randomised controlled trials (RCTs) have examined the effectiveness of some of these interventions. ${ }^{6}$ Therefore, little evidence is available for informed policy decisions in this African subregion. ${ }^{7}$ A comprehensive synthesis and appraisal of the studies on interventions for IHD in SSA may be necessary towards informing better response and strengthening existing interventions. We systematically reviewed available literature on IHD in SSA to identify, synthesise and appraise population-wide and individual-level interventions addressing risk factors of IHD among adults, towards better public health policy and practise in the region.

\section{METHODS}

\section{Research question}

IHD is a largely preventable NCD, with deaths estimated to rise in sSA by over $70 \%$ by the year $2030 .{ }^{7}$ In line with the aim, this study seeks to address the question: are there evidence-based interventional measures currently available to address known risk factors for this preventable disease in the African subregion?

\section{Search strategy}

A systematic search of MEDLINE, EMBASE, Global Health and African Journals Online (AJOL) was conducted in May 2016 to identify relevant studies on IHD in sSA, with search date set from 1980 to 2015 (table 1).

Further searches were conducted on Google Scholar, and the reference lists of selected studies were further hand searched for relevant articles. Countries in sSA were as provided in the World Bank list of countries, regions and economies. ${ }^{16}$

\section{Selection criteria}

We included original studies (RCTs, cross-sectional or cohort studies and quasiexperimental studies) that described basic interventions used in modifying risk factors associated with IHD across different countries in sSA. The outcome measures assessed were changes in blood pressure (BP), blood glucose, total cholesterol and body mass index (BMI). We ensured participants in selected studies were adults aged 18 years and above. We excluded studies that focused on interventions in children. Reviews, commentaries, viewpoints and letters were also excluded. There were no English Language restrictions, and no attempt was made to contact authors of articles that were not selected.

\section{Table 1 Search terms on MEDLINE}

\begin{tabular}{ll}
\hline Number & Searches \\
\hline 1 & $\begin{array}{l}\text { cardiovascular diseases/ or myocardial ischemia/ or angina pectoris/ or coronary disease/ or coronary artery } \\
\text { disease/ or myocardial infarction/ } \\
\text { ischemic heart disease*.mp. (mp=title, abstract, original title, name of substance word, subject heading word, } \\
\text { keyword heading word, protocol supplementary concept word, rare disease supplementary concept word, unique } \\
\text { identifier] } \\
\text { coronary heart disease*.mp. (mp=title, abstract, original title, name of substance word, subject heading word, } \\
\text { keyword heading word, protocol supplementary concept word, rare disease supplementary concept word, unique } \\
\text { identifier) } \\
\text { ischaemic heart disease*.mp. (mp=title, abstract, original title, name of substance word, subject heading word, } \\
\text { keyword heading word, protocol supplementary concept word, rare disease supplementary concept word, unique } \\
\text { identifier) } \\
\text { "africa south of the sahara"/ or africa, central/ or cameroon/ or central african republic/ or chad/ or congo/ or } \\
\text { "democratic republic of the congo"/ or equatorial guinea/ or gabon/ or africa, eastern/ or comoros/ or burundi/ or } \\
\text { djibout// or eritrea/ or ethiopia/ or kenya/ or rwanda/ or seychelles/ or somalia/ or south sudan/or sudan/ or } \\
\text { tanzania/ or uganda/ or africa, southern/ or angola/ or botswana/ or lesotho/ or madagascar/ or malawi/ or } \\
\text { mauritius/ or mozambique/ or namibia/ or sao tome and principe/ or south africa/ or swaziland/ or zambia/ or } \\
\text { zimbabwe/ or africa, western/ or benin/ or burkina faso/ or cape verde/ or cote d'ivoire/ or gambia/ or ghana/ or } \\
\text { guinea/ or guinea-bissau/ or liberia/ or mali/ or mauritania/ or niger/ or nigeria/ or senegal/ or sierra leone/ or togo/ } \\
\text { subsaharan africa.mp. (mp=title, abstract, original title, name of substance word, subject heading word, keyword } \\
\text { heading word, protocol supplementary concept word, rare disease supplementary concept word, unique identifier) }\end{array}$ \\
$\begin{array}{l}1 \text { or } 2 \text { or } 3 \text { or } 4 \\
5\end{array}$ \\
7 or 6
\end{tabular}




\section{Case definitions}

We mainly considered studies that focused on interventions addressing known risk factors IHD, including high $\mathrm{BP}$, diabetes mellitus, hypercholesterolaemia, overweight and obesity and tobacco smoking. ${ }^{17}$ IHD was defined as a group of heart and vascular events characterised by narrowing of arteries with reduced blood and oxygen supply to the heart muscle. ${ }^{18}$ Diagnosis, when described, may be based on ECG findings, echocardiogram or relevant imaging findings, cardiac enzymes and/or tissue-specific cardiac biomarkers. ${ }^{18} 19$ IHD is also often referred to as 'coronary artery disease' or 'coronary heart disease' (CHD); in such cases, we generally checked for any reported evidence of intervention targeting risk of ischaemic myocardial necrosis to satisfy inclusion in our review.

\section{Quality assessment}

The quality of selected studies was assessed using the Jadad scale. ${ }^{20}$ Studies were graded between 1 and 5, with 5 being the highest and 1 the lowest. Criteria employed were randomisation, blinding and accountability of all participants. Details of the grading of each study are in the online supplementary file.

\section{Data extraction and synthesis}

Data were double extracted from each study and stored in Microsoft Excel file format. We extracted data on overall study characteristics including study period, country, location and setting, method of participant recruitment, number and mean age of participants, intervention implemented, follow-up period and assessment of outcome variables. We did not conduct any meta-analysis in this review due to varying heterogeneities observed within and between population groups in the selected studies. A qualitative synthesis, as well as evidence appraisal based on relevant information obtained from selected studies was conducted (see online supplementary file). A PRISMA checklist was used to assess the completeness of all stages of our review.

\section{RESULTS}

Our search returned 2311 records. Only nine studies met our inclusion criteria and were retained for qualitative synthesis. $^{21-29}$ The reasons for the excluded studies are as highlighted in figure 1. Individual study characteristics are shown in table 2.

Our findings showed that population-wide and individual-level interventions conducted across selected studies included dietary modification, physical activity, health education and health promotion activities on tobacco and alcohol cessation. These interventions were primarily aimed at reducing metabolic risk factors for IHD, such as hypertension, diabetes, obesity and hypercholesterolaemia (table 2 and see online supplementary file).

Five of the retained studies employed dietary modification in addressing hypertension and hypercholesterolaemia associated with IHD. ${ }^{21} 22 \quad 242729$ Four studies focused on salt intake and its relationship with $\mathrm{BP}^{21} 222427$ while the fifth study focused on modifying

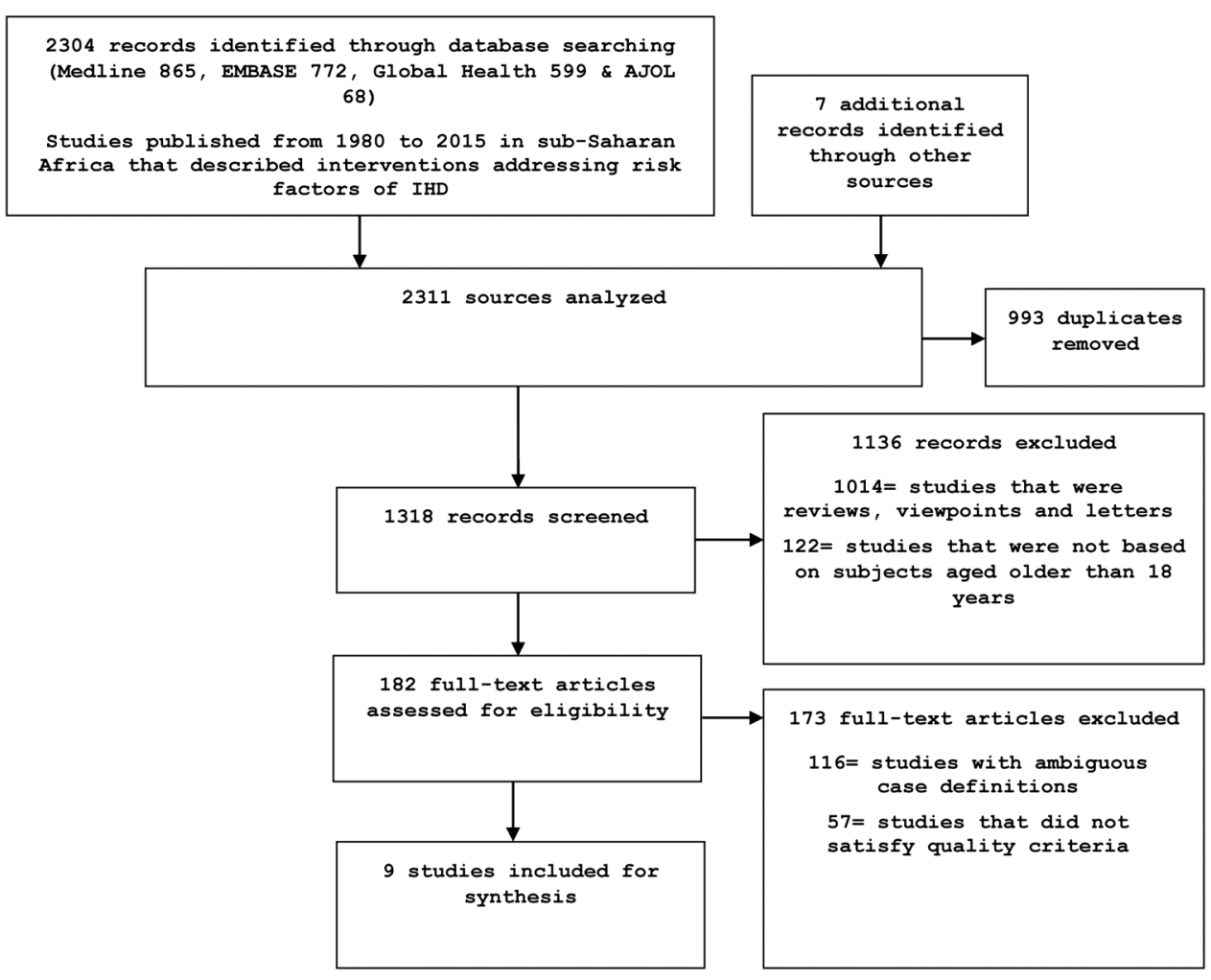

Figure 1 Flow chart of study selection. 
Table 2 Characteristics of included studies

\begin{tabular}{|c|c|c|c|c|}
\hline Studies & Country, location (setting) & Study design & Type of intervention & Results \\
\hline Adeyemo et $a^{21}$ & $\begin{array}{l}\text { Nigeria, Igbo-Ora and Idere } \\
\text { (rural) }\end{array}$ & Feasibility study & Dietary modification & $\begin{array}{l}\text { Reduction observed in 24-hour urinary sodium excretion, } \\
\text { and in systolic and diastolic blood pressure }\end{array}$ \\
\hline Cappuccio et $a^{22}$ & $\begin{array}{l}\text { Ghana, Ejisu-Juabeng and } \\
\text { Kumasi districts (rural and } \\
\text { semiurban) }\end{array}$ & Cluster randomised trial & $\begin{array}{l}\text { Dietary modification } \\
\text { and health promotion }\end{array}$ & $\begin{array}{l}\text { Significant reduction in systolic and diastolic blood } \\
\text { pressure, and changes observed in 24-hour urinary } \\
\text { sodium excretion }\end{array}$ \\
\hline Dowse et $a^{P^{3}}$ & Mauritius (semiurban) & Cross-sectional survey & $\begin{array}{l}\text { Health education and } \\
\text { health promotion }\end{array}$ & $\begin{array}{l}\text { Reduction in blood pressure, increased physical activity, } \\
\text { but no effect observed on BMI. There was an unusual } \\
\text { increase in blood sugar }\end{array}$ \\
\hline Forrester et $a P^{4}$ & $\begin{array}{l}\text { Nigeria, Igbo-Ora and Idere } \\
\text { (rural) }\end{array}$ & Randomised control trial & Dietary modification & $\begin{array}{l}\text { No significant association observed between changes in } \\
\text { salt and blood pressure }\end{array}$ \\
\hline Grace et $a R^{5}$ & $\begin{array}{l}\text { South Africa, Mpumalanga and } \\
\text { Gauteng (rural) }\end{array}$ & Non-randomised trial & $\begin{array}{l}\text { Physical activity and } \\
\text { health promotion }\end{array}$ & $\begin{array}{l}\text { Minimal reductions observed in BMI and blood pressure. } \\
\text { No reduction observed in total serum cholesterol }\end{array}$ \\
\hline Mendis et $a{ }^{26}$ & Nigeria (semiurban) & Cluster randomised trial & $\begin{array}{l}\text { Health education and } \\
\text { health promotion }\end{array}$ & Significant reduction observed in blood pressure levels \\
\hline Mtabaji et $a^{7}$ & Tanzania (semiurban) & Randomised control trial & Dietary modification & $\begin{array}{l}\text { A significant reduction in arterial blood pressure among } \\
\text { male normotensives placed on low salt diet compared to } \\
\text { those on high salt diet }\end{array}$ \\
\hline Rossouw et $a^{28}$ & $\begin{array}{l}\text { South Africa, South-Western } \\
\text { Cape (rural) }\end{array}$ & Quasi-experimental design & $\begin{array}{l}\text { Health education and } \\
\text { health promotion }\end{array}$ & $\begin{array}{l}\text { Reduction in blood pressure in both sexes, and minimal } \\
\text { reduction in BMI among females }\end{array}$ \\
\hline Uusitalo et $a^{R^{9}}$ & Mauritius (semiurban) & Cross-sectional survey & Dietary modification & Positive reduction observed in total serum cholesterol \\
\hline
\end{tabular}


the content of a commonly used cooking oil targeted at reducing total cholesterol concentration. ${ }^{29}$

In the study by Adeyemo $e t a l,{ }^{21}$ the effects of reducing cooking salt among free-living normotensive individuals in two rural communities in south-western Nigeria were examined. There was at least $50 \mathrm{mmol}$ reduction in 24-hour urinary sodium in $67 \%$ of the participants, and $25 \mathrm{mmol}$ reduction in $84 \%$ of the participants. Reductions were also observed in the systolic and diastolic BP of participants, with the mean systolic BP reducing by 4.7 and $7.0 \mathrm{~mm} \mathrm{Hg}$ among men and women, respectively, after 2 weeks. A similar finding was reported in Tanzania by Mtabaji et $a l,{ }^{27}$ with a significant reduction in arterial $\mathrm{BP}$ among male normotensives placed on low salt diet compared to those on high salt diet. The study further reported that those on low salt diet had a urinary sodium excretion of $52 \mathrm{mmol} /$ day relative to a $320 \mathrm{mmol} /$ day observed among those on high salt diet. In Ghana, Cappuccio et $a l^{22}$ also examined the effects of not adding salt while cooking, and reducing the consumption of preserved salted foods on urinary sodium excretion and BP among 1013 adult participants in both rural and semiurban settings. Significant reduction in the systolic and diastolic BP, as well as urinary sodium, was observed in the intervention group compared with control, especially after 6 months of restriction of salt intake. The study concluded that a relative decrease in BP may be observed with reduced salt intake in the West Africa subregion. However, in a Nigerian study involving 58 participants from two rural communities, Forrester et $a t^{24}$ reported that no significant association was observed between measured changes in dietary salt and systolic or diastolic BP $(p=0.08)$. In this study, outcome measures showed that the mean change in systolic and diastolic BP for both the low salt and high salt phases differed by 4.8 and $3.2 \mathrm{~mm} \mathrm{Hg}$, respectively. ${ }^{24}$

In Mauritius, Uusitalo et $a l^{29}$ examined the effect of modifying commonly used cooking oil (ration oil) on mean serum cholesterol concentration among 1926 participants. The main composition of the ration oil was mostly palm oil which was high in saturated and monounsaturated fatty acids. The ration oil was modified to entirely soya bean oil. At baseline, $86 \%$ of participants used ration oil. During the 5-year follow-up, 53\% of participants used the modified ration oil. The mean cholesterol concentration at baseline was $5.5 \mathrm{mmol} / \mathrm{L}$, with this reducing to $4.7 \mathrm{mmol} / \mathrm{L}$ at follow-up. This reduction was statistically significant for both men and women $(\mathrm{p}<0.001)$.

Only one study examined the effect of physical activity on some selected health measures such as BP, body mass index (BMI) and plasma cholesterol concentration. ${ }^{25}$ The study was conducted among 143 male South African colliery executives recruited across two South African provinces, Mpumalanga and Gauteng. The participants were exposed to a physical fitness programme in the control group and a physical fitness programme combined with a health promotion intervention programme in the experimental group for 32 weeks. At 32 weeks, there was a reduction in BMI in the experimental group, although, this was not statistically significant $\quad(p=0.067)$. The study also observed an improvement in both the systolic and diastolic BP of participants after 16 weeks. Although no statistical significance was observed in the experimental group, the values at reassessment were better than the baseline values. Moreover, effects of physical activity combined with health promotion measures on total cholesterol concentration in the participants were examined over the same 32-week period. ${ }^{25}$ There were no changes in total cholesterol observed during the 16 and 32 weeks reassessment in the experimental group. A moderate increase was observed in the cholesterol concentration of the control group during the 16-week reassessment.

The third intervention identified was health education/promotion measures. Three studies were identified, and targeted essentially the effects of tobacco smoking cessation and alcohol consumption reduction on hypertension, hypercholesterolaemia, diabetes and obesity. ${ }^{23} 2628$ Other selected studies also had some forms of health education messages along with their targeted intervention, although these were non-specific.

In Mauritius, Dowse et $a t^{23}$ examined the effects of some health education/promotion activities on the prevalence of IHD risk factors among 5162 participants over a 5-year period (1987-1992). The study employed the use of mass media campaigns, widespread community, school and workplace health education activities to promote increased physical activity, healthy diet, smoking cessation and reduction in alcohol consumption. While the interventions resulted in a significant reduction in the prevalence of hypertension in both men and women participants $(\mathrm{p}<0.001)$, no positive effects were observed in BMI, and no statistically significant reduction was observed in mean fasting blood glucose. ${ }^{25}$ In a larger South African study involving 7188 participants, Rossouw et $a l^{28}$ observed a reduction in BP in both men and women participants, and a reduction in BMI only among the women participants after a 4-year health education/promotion intervention programme.

In Nigeria, Mendis et $a l^{26}$ investigated the effectiveness of WHO CVD risk management health promotion package in reducing BP in primary care settings, and in improving adherence to lifestyle changes at the individual and cluster levels among 1188 participants. The intervention involved assessment and management of cardiovascular risk factors, and counselling on risk factors control such as physical activity, diet and tobacco cessation. There was a reduction in BP which was more in the intervention group than the control group. In the intervention group, all participants reported quitting smoking, while $74.4 \%$ reported quitting smoking in the control group $(\mathrm{p}=0.023)$. 


\section{DISCUSSION}

This systematic review examined population-wide and individual-level interventions that focused on modification of risk factors associated with IHD in sSA. Our findings suggest there may be effective IHD-preventive strategies specific for African population groups, with dietary modification, physical activity, health education/ promotion activities being the main measures reported.

The findings from studies on effects of dietary modifications indicate that meals low in fats and salts may reduce major IHD risks, including hypertension and hypercholesterolaemia. $^{21} 22 \quad 242729$ However, not all studies reported a statistically significant relationship, suggesting there are still uncertainties on the role of dietary salts and fats in reducing risks of IHD. Hooper and colleagues, however, reported that evidence obtained from large and small trials revealed that low sodium diet may help in lowering BP after withdrawing antihypertensives. Hooper further noted that a comprehensive dietary and nutritional plan addressing salt and fat consumption may be very helpful at reducing risks of CVDs in a population. ${ }^{30}$

Physical activity, as a sole intervention for modifying risks of CVDs, was implemented in just one study, with the authors not clearly stating how physical activity can effectively modify risk factors associated with IHD among adults. ${ }^{25}$ However, several studies have revealed that moderate physical activity and exercise most days of the week may be associated with significant reduction in the incidence and mortality from CVDs. ${ }^{31} 32$ In the study of 17944 middle-aged male British civil servants, free of CHD, the age-standardised cumulative incidence of CHD was $3.1 \%$ among men observing vigorous physical activity, compared with $6.9 \%$ among those with no physical activity. ${ }^{33}$ Although, this may not be directly compared with sSA, due to several contextual differences, it still possibly suggests such measures could lead to similar outcomes in the African subregion.

From the included studies, we also noted that population-wide health education and health promotion measures can indirectly influence healthy lifestyles and behavioural changes. ${ }^{23} 2628$ Ford $e t a \vec{l}^{4}$ employed a health promotion model that can relatively address common risk factors for CVDs, with this accounting for population-wide improvements in BP, cholesterol, smoking and physical activity, and sufficient to influence a change from $44 \%$ to $76 \%$ in reduction of CHD mortality.

Most of the interventions reported in this review were community based, suggesting that they may only be feasible and acceptable within contextually similar settings. The organisation and sustainability of these interventions across many settings in sSA may be difficult due to prevailing divergent social, cultural and individual issues. Hence, underlying determinants of IHD, including income distribution and educational level specific to the various population subgroups in the region, need to be identified and addressed..$^{35}$ Additionally, interventions targeting behavioural risks in the general population through a comprehensive risk assessment, and designing cost-effective management protocols for the high-risk categories may need to be undertaken towards ensuring improved cardiovascular health in sSA. ${ }^{35}$ Advocacies and policies that allow collaboration and regular interactions among experts in the academia, researchers, clinicians, community leaders, government and non-governmental agencies, may be helpful in instituting some of these interventions effectively on a population-wide scale in many indigenous settings in the region. ${ }^{36}$ Such policy frameworks may need to be jointly developed by the various stakeholders to aid effective implementation, monitoring and evaluation across the subcontinent.

Our study is not without limitations. Despite a rigorous search across several electronic databases, the number of studies retained was relatively small to fully reflect the entire sSA population. Moreover, only five countries were represented in this review (Ghana, Mauritius, Nigeria, South Africa and Tanzania), meaning that findings are more likely to reflect the conditions in these settings. There were obvious heterogeneities across the selected studies. As such, a meta-analysis, which could have provided a regional pooled estimate on the effectiveness of these interventions in SSA, was not conducted. We cannot, therefore, state with all certainty specific interventions for IHD that can be applied, modelled or replicated in sSA. We also understand there are several interventions that have been studied in many settings outside sSA; a contextual comparison of these to African countries would have been worthwhile, but discussing this would simply be beyond the aims of this study. Additionally, WHO already provided a comprehensive Package of Essential Non-communicable disease interventions for primary healthcare in less developed settings, with a focus on improving maternal nutrition, implementing tobacco prevention and cessation programmes, improving affordability of food, encouraging physical activity and providing access to effective prevention and care of risks and diseases; ${ }^{37}$ our review would have been more detailed if assessments of these interventions were identified across selected studies. However, due to very low research output and a relative lack of understanding of the burden of IHD in sSA, we believe our report may contribute to relevant research and policy response on IHD risk factors and interventions across countries in the region.

\section{CONCLUSION}

The rising burden of IHD in sSA without effective population-wide interventions remains a huge public health concern in the region. Hitherto, little has been known on the epidemiology, treatment options and overall public health response to IHD in Africa. Our findings on dietary modifications, physical activity and relevant health promotion measures may have been suggestive of relative improvements in reducing risks of 
IHD, yet, we still cannot generalise and recommend this to many African settings, especially due to varying degrees of heterogeneity within and across population groups. We recommend more research and active collaboration on IHD, particularly on the understanding of its epidemiological distribution and overall burden in sSA, targeted towards developing and/or strengthening population-wide preventive and treatment options across several settings in the region.

\section{Author affiliations}

${ }^{1}$ Centre for Population Health Sciences, Usher Institute, University of Edinburgh, Edinburgh, UK

${ }^{2}$ Department of Biochemistry, College of Health Sciences, Osun State University, Osogbo, Nigeria

${ }^{3}$ Department of Computer and Information Sciences, and the eHealth Research Cluster, Covenant University, Ota, Nigeria

${ }^{4}$ Demography and Social Statistics, and the e-Health Research Cluster, Covenant University, Ota, Nigeria

${ }^{5}$ Centre for Global Health Research and the World Health Organization Collaborating Centre for Population Health Research and Training, Usher Institute, University of Edinburgh, Edinburgh, UK

Twitter Follow Davies Adeloye at @davyadeloy

Acknowledgements The authors wish to thank Drs Karen Fairhurst and Christine Campbell of the Centre for Population Health Sciences, University of Edinburgh, UK, for the intellectual support during the conduct of this study.

Contributors JE conducted the literature search with oversight from DA. JE wrote the first draft of the manuscript. AVA, NO and DA contributed to the final writing of the paper and checked for important intellectual content.

Funding This research received no specific grant from any funding agency in the public, commercial or not-for-profit sectors.

Competing interests None declared.

Provenance and peer review Not commissioned; externally peer reviewed.

Data sharing statement No additional data are available.

Open Access This is an Open Access article distributed in accordance with the Creative Commons Attribution Non Commercial (CC BY-NC 4.0) license, which permits others to distribute, remix, adapt, build upon this work noncommercially, and license their derivative works on different terms, provided the original work is properly cited and the use is non-commercial. See: http:// creativecommons.org/licenses/by-nc/4.0/

\section{REFERENCES}

1. Lawes CMM, Vander Hoorn S, Law MR, et al. Blood pressure and the global burden of disease 2000. Part 1: Estimates of blood pressure levels. J Hypertens 2006;24:413-22.

2. World Health Organization. A global brief on Hypertension: silent killer, global public health crises (World Health Day 2013). Geneva: WHO, 2013.

3. GBD 2013 Mortality and Causes of Death Collaborators. Global, regional, and national age-sex specific all-cause and cause-specific mortality for 240 causes of death, 1990-2013: a systematic analysis for the Global Burden of Disease Study 2013. Lancet 2015;385:117-71

4. Global Burden of Disease Study 2013 Collaborators. Global, regional, and national incidence, prevalence, and years lived with disability for 301 acute and chronic diseases and injuries in 188 countries, 1990-2013: a systematic analysis for the Global Burden of Disease Study 2013. Lancet 2015;386:743-800.

5. Opie LH, Seedat YK. Hypertension in sub-Saharan African populations. Circulation 2005;112:3562-8.

6. Mensah GA. Ischaemic heart disease in Africa. Heart 2008;94:836-43.

7. Onen CL. Epidemiology of ischaemic heart disease in sub-Saharan Africa. Cardiovasc J Afr 2013;24:34-42.
8. de-Graft Aikins A, Unwin N, Agyemang C, et al. Tackling Africa's chronic disease burden: from the local to the global. Global Health 2010;6:5.

9. World Health Organization. Global status report on noncommunicable diseases 2010. Geneva: WHO, 2011.

10. Kayima J, Wanyenze RK, Katamba A, et al. Hypertension awareness, treatment and control in Africa: a systematic review. BMC Cardiovasc Disord 2013;13:54.

11. MacMahon S, Alderman MH, Lindholm LH, et al. Blood-pressurerelated disease is a global health priority. Lancet 2008;371: $1481-3$.

12. Teo KK, Ounpuu S, Hawken S, et al. Tobacco use and risk of myocardial infarction in 52 countries in the INTERHEART study: a case-control study. Lancet 2006;368:647-58.

13. Shroufi A, Chowdhury R, Anchala R, et al. Cost effective interventions for the prevention of cardiovascular disease in low and middle income countries: a systematic review. BMC Public Health 2013;13:285

14. Yusuf S, Hawken S, Ounpuu S, et al. Effect of potentially modifiable risk factors associated with myocardial infarction in 52 countries (the INTERHEART study): case-control study. Lancet 2004;364:937-52.

15. Adeloye D, Basquill C. Estimating the prevalence and awareness rates of hypertension in Africa: a systematic analysis. PLOS ONE 2014;9:e104300.

16. World Bank. World's Bank classification on countries economies. Secondary World's Bank classification on countries economies. 2015. http://data.worldbank.org/about/country-classifications.

17. Jones DW, Chambless LE, Folsom AR, et al. Risk factors for Coronary Heart Disease in African Americans: the atherosclerosis risk in communities study, 1987-1997. Arch Intern Med 2002;162:2565-71.

18. Qaseem A, Finn SD, Williams S, et al. Diagnosis of stable ischemic Heart Disease: Summary of a Clinical Practice Guideline From the American College of Physicians/American College of Cardiology Foundation/American Heart Association/American Association for Thoracic Surgery/Preventive Cardiovascular Nurses Association/Society of Thoracic Surgeons. Ann Intern Med 2012;157:729-34.

19. Mendis S, Thygesen K, Kuulasmaa K, et al. World Health Organisation definition of myocardial infarction: 2008-09 revision Int J Cardiol 2011:40:139-46. http://dx.doi.org/10.1093/ije/dyq165

20. Jadad AR, Moore RA, Carroll D, et al. Assessing the quality of reports of randomized clinical trials: is blinding necessary? Control Clin Trials 1996;17:1-12.

21. Adeyemo AA, Prewitt TE, Luke A, et al. The feasibility of implementing a dietary sodium reduction intervention among free-living normotensive individuals in south west Nigeria. Ethn Dis 2002;12:207-12.

22. Cappuccio FP, Kerry SM, Micah FB, et al. A community programme to reduce salt intake and blood pressure in Ghana. BMC Public Health 2006;6:13-23.

23. Dowse GK, Gareeboo H, Alberti KGMM, et al. Changes in population cholesterol concentration and other cardiovascular risk factor levels after five years of the non-communicable disease intervention programme in mauritius. Mauritius Non-communicable Disease Study Group. BMJ 1995;311:1255-9.

24. Forrester T, Adeyemo A, Soarres-Wynter S, et al. A randomised trial on sodium reduction in two developing countries. J Hum Hypertens 2005;19:55-60.

25. Grace JM, Wilder CJ, Strydom GI. The effect of a physical and a combined health promotion intervention programme on some selected health indicators on South African colliery executives. South Afr J Res Sports, Phys Educ Recreation 2009;31:9-18.

26. Mendis S, Johnston SC, Fan W, et al. Cardiovascular risk management and its impact on hypertension control in primary care in low-resource settings: a cluster-randomised trial. Bull World Health Organisation 2010;88:412-19.

27. Mtabaji JP, Nara Y, Yamori Y. The cardiac study in Tanzania: salt intake in the causation and treatment of hypertension. $J$ Hum Hypertens 1990;4:80-1.

28. Rossouw JE, Jooste PL, Chalton DO, et al. Community-Based Intervention: The Coronary Risk Factor Study (CORIS). Int $J$ Epidemiol 1993;22:428-38.

29. Uusitalo U, Feskins EJ, Tuomilehto J, et al. Fall in total cholesterol concentration over five years in association with changes in fatty acid composition of cooking oil in Mauritius: Cross sectional survey. BMJ 1996;313:1044-6.

30. Hooper L, Bartlett C, Davey SG, et al. Advice to reduce dietary salt for prevention of cardiovascular disease. Cochrane Database Syst Rev 2004;(1):CD003656. 
31. Haennel RG, Lemire F. Physical activity to prevent cardiovascular disease. How much is enough? Can Fam Physician 2002;48:65-71.

32. Thompson PD, Buchner D, Pina IL, et al. Exercise and physical activity in the prevention and treatment of atherosclerotic cardiovascular disease: a statement from the Council on Clinical Cardiology (Subcommittee on Exercise, Rehabilitation, and Prevention) and the Council on Nutrition, Physical Activity, and Metabolism (Subcommittee on Physical Activity). Circulation 2003;107:3109-16.

33. Morris JN. Exercise in the prevention of coronary heart disease: today's best buy in public health. Med Sci Sports Exerc 1994;26:807-14.
34. Ford ES, Ajani UA, Croft JB, et al. Explaining the decrease in US deaths from coronary disease, 1980-2000. N Engl J Med 2007;356:2388-98.

35. Mendis S, Puska P, Norrving B, eds. Global atlas on cardiovascular disease prevention and control. Geneva: World Health Organization, 2011.

36. Swerissen $\mathrm{H}$, Crisp BR. The sustainability of health promotion for different levels of social organization. Health Promot Int 2004;19:123-30.

37. World Health Organization. Package of Essential Noncommunicable (PEN) disease interventions for primary health care in low-resource settings. Geneva, Switzerland: WHO, 2010. 